\title{
Cooperative Management of Invasive Species: A Dynamic Nash Bargaining Approach
}

\author{
Kelly M. Cobourn ${ }^{1}$ (D) Gregory S. Amacher ${ }^{1}$. \\ Robert G. Haight ${ }^{2}$
}

Accepted: 28 February 2018 / Published online: 7 March 2018

(C) Springer Science+Business Media B.V., part of Springer Nature 2018

\begin{abstract}
We use a Nash bargaining framework to examine scope for bargaining in invasive species problems where spread depends on the employment of costly controls. Municipalities bargain over a transfer payment that slows spread but requires an infested municipality to forgo nonmarket benefits from the host species. We find that when the uninfested municipality has a relative bargaining power advantage, bargaining may attain the first-best solution. However, in many cases a short-term bargaining agreement is unlikely to succeed, which suggests a role for higher levels of government to facilitate long-term agreements even when the details are left to municipalities to negotiate.
\end{abstract}

Keywords Bioeconomics · Biological invasions $\cdot$ Emerald ash borer · Negotiation · Optimal control · Pest spread

JEL Classification Q57 · Q23 · C71

\section{Introduction}

Invasive species cause billions of dollars in damages in the U.S. and world and span all types of land and water resources. Not surprisingly, there are several examples of intergovernmental cooperation to stem the spread of invasives. As early as 1999, the U.S. government passed legislation mandating coordination of control efforts through the National Invasive Species Council. This program links various federal government agencies and provides channels for

Electronic supplementary material The online version of this article (https://doi.org/10.1007/s10640018-0238-8) contains supplementary material, which is available to authorized users.

\footnotetext{
$\bowtie$ Kelly M. Cobourn

kellyc13@vt.edu

1 Department of Forest Resources and Environmental Conservation, Virginia Tech, 310 West Campus Drive, Blacksburg, VA 24061, USA

2 USDA Forest Service Northern Research Station, Saint Paul, MN, USA
} 
these agencies to work with states to address national-scale issues related to invasive species management. It is also becoming increasingly common for states to have local cooperatives aimed at encouraging landowner cooperation across municipal and county governments. For example, there are many levels of governments across different states involved in controlling invasive species in the Great Lakes. In 2012, it was proposed that 9.5 billion dollars in spending be allocated to isolate and control existing invasive populations such as Asian Carp, in order to prevent spread in connected rivers and lakes (Great Lakes Commission 2012). Another example is Florida's Cooperative Invasive Species Management Areas program. This program is designed to facilitate cooperation among stakeholders to monitor and control invasive species in geographically linked regions such as the Everglades.

There is now a relatively large literature in economics centered on control strategies in invasive species and native pest control problems (Aadland et al. 2015; Bhat and Huffaker 2007; Bhat et al. 1993, 1996; Büyüktahtakin and Haight 2017; Epanchin-Niell and Wilen 2012, 2014; Feder and Regev 1975; Grimsrud et al. 2008; Olson 2006; Sims et al. 2010). Much of this literature examines two polar cases characterizing control choices. In the first case, agents choose their privately optimal control without considering the impact of their choices on other at-risk landowners. In the second case, a social planner is assumed to control actions for landowners at a landscape level, thus internalizing all externalities by choosing control to maximize social welfare. Epanchin-Niell and Wilen (2014) point out that this dichotomy fails to capture the often-observed case in which landowners cooperate with other agents to control the spread of a pest. For example, Epanchin-Niell et al. (2010) present survey evidence that California ranchers sometimes cooperatively manage the spread of yellow starthistle across property boundaries by sharing control costs or by coordinating control activities. Similarly, Fiege (2005) documents the cooperative management of weeds by individual landholders in Montana, and Bhat et al. (1996) consider cooperation to limit the migration of native beaver populations across property boundaries.

The typical way that incentives to cooperate have been considered in the economic literature is through a bargaining mechanism. Such an approach has been applied to terrestrial species (Bhat and Huffaker 2007; Bhat et al. 1996), pelagic species (Hamalainen et al. 1984; Mazzanti 2001; Munro 1979), and water (Frisvold and Caswell 2000). A number of studies have also considered the role of transfer payments as a bargaining tool. For example, Bhat and Huffaker (2007) consider variable transfer payments between adjacent landowners and Liu and Sims (2016) consider side payments to induce voluntary coordination to control a transboundary invader. Wilen (2007) discusses the potential for chained bilateral transfer payments between individual landowners facing the threat of invasive species spread. This process involves a transfer payment from one landowner to another for every unit of time that the invasion is delayed. In a scenario with high transaction costs, Wilen argues that negotiations are likely to unfold in a pairwise manner, so that one agent negotiates with a neighbor to slow the arrival of the invasive on their property. As the invasive spreads, new negotiations occur between agents at the fringe of the infestation.

In this study, we present a simple yet dynamic model of bilateral bargaining to prevent the spread of a pest between two neighboring municipalities, one of which is infested and one of which is uninfested. ${ }^{1}$ We choose to focus on a bilateral bargaining problem for two primary reasons. First, this type of agreement is consistent with the types of interactions that might prevail in an environment characterized by transactions costs that have been noted as a deterrent to widespread, multilateral bargaining (Wilen 2007). Second, considering the

1 Alternatively, this problem could be framed as one in which two coalitions bargain to prevent spread of an invasive species between their members to reflect a multilateral or multiple municipality problem. 
bilateral problem, rather than the complex multilateral problems modeled by Epanchin-Niell and Wilen (2014) and Kovacs et al. (2014), allows us to characterize and explore in greater detail incentives to bargain and the factors that drive differences in the bargaining outcome relative to the privately optimal and social planner outcomes. We apply this bilateral bargaining model to a problem of slowing invasive species spread, though the general framework may be applied to the case of an endemic pest with cyclical population dynamics where a bargaining agreement between adjacent actors can suppress the probability of an outbreak.

In this setting, we develop a theory of cooperation in invasive species problems that relies on an axiomatic Nash bargaining game (Nash 1950) under the premise that the threat exists for an invasive species to spread from an infested to an uninfested municipality. The simplicity of an axiomatic Nash bargaining approach allows us to characterize negotiation between municipalities while also focusing on the important dynamic issues inherent in the spread of the pest, and where we would not expect municipalities to enter into a perfect cooperation outcome that is consistent with a social planning problem. Nash bargaining is a common construct in problems like ours where improvements in net rents drive negotiation over alternative offers and counteroffers. ${ }^{2}$ Examples are found in (Gertler and Trigari 2006) for multi-period wage bargaining negotiations; Koskela and Schöb (1999) and Koskela et al. (1998) for emissions tax bargaining and wage bargaining with polluting firms; and Amacher et al. (2012) for the presence of bribes in forest harvesting concessions.

The Nash bargaining problem is an open loop solution, as opposed to one where government players could update their agreement over time. The open loop problem makes sense given the obvious administrative and transaction costs governments would face in adjusting agreements, especially because these may require public referendums in practice. Moreover, commitment in the invasive species case is not likely required to be infinite as is often used as justification for closed loop formulations in the environmental regulation literature (see Calvo and Rubio 2012). Most importantly, it has been shown that open loop Nash bargaining outcomes often understate the benefits from coordination in environmental policy problems (van der Ploeg and de Zeeuw 1992), and that closed loop solutions often imply more opportunities for coordination among parties (Calvo and Rubio 2012). Our solution is therefore the most conservative in terms of estimating the gains from cooperation. We demonstrate in the supplementary appendix that this is indeed the case in our empirical application, though the results from a closed loop and open loop modeling approach are quite similar. ${ }^{3}$ Given

\footnotetext{
2 Nash proved that under certain conditions any agreement maximizes the product of net rents defined as the gains from cooperation relative to the disagreement outcome (e.g., see Binmore et al. 1986; Osborne and Rubinstein 1994). The required conditions are: invariance of the solution to monotonic transforms of utility, a fact that holds here given that the net rent functions of each municipality would likely not change structurally over time given the administrative nature of negotiation and the relatively short time periods involved; the impossibility of Pareto improvements should a bargaining solution exist, which is guaranteed by the definition of the objective function for our problem and the fact that governments would be bargaining on behalf of their residents; and independence of irrelevant alternatives. Independence of irrelevant alternatives is usually fairly stringent, but it holds in our problem since the net gains we define would mean that inefficient agreement points can be removed from consideration given that the agreement outcome by definition must improve net present value rents over the disagreement outcome, and this defines the contract set. As in most problems of this type, commitment on the part of both municipalities to the solution of the bargaining problem must hold. This is likely in our case because the negotiated agreement is between governments and thus a legal and administrative system exists to implement the solution that would be slow to change or difficult to circumvent.

3 The results for the closed loop model are presented in the supplementary appendix. In the baseline model simulation, the social costs in the open loop model are 0.737 versus 0.542 in the closed loop model, which implies that the open loop model overstates the gains from bargaining by $3.2 \%$ in our application. These results are similar across sensitivity analyses.
} 
the similarity of the results, we opt to use an open loop approach because of its analytical tractability and utility in developing intuition into the bargaining problem.

In a non-cooperative environment without bargaining, the infested municipality chooses control efforts to maximize its own expected rents. In this scenario, the infested municipality invests too little control effort from a social perspective because its choice of control effort influences the probability that the invasive species will spread to the uninfested municipality. There would potentially be gains for the uninfested municipality to bargain with the infested municipality if the former offered to share in the latter's control costs in exchange for a higher level of control that would reduce the probability that the invasive species spreads.

We retain the common assumption from the economics literature that cooperation between the municipalities occurs through a transfer payment. We use our bargaining model to examine how the divergence between outcomes in the Nash bargaining game and the fully cooperative, socially optimal, level of control depends on key parameters in the model, such as the rate at which an invasive species is expected to spread over time and the degree of bargaining power each municipality may possess. We then calibrate a numerical simulation model that represents a current and important invasive species management problem, namely that of emerald ash borer in the Twin Cities of Minneapolis and St. Paul, Minnesota.

Our results indicate that bargaining achieves the first-best solution only when the uninfested municipality possesses a substantial advantage in terms of relative bargaining power. We also find that species-specific parameters such as the rate at which the probability of spread grows over time and the efficacy of control in reducing the pest's spread play important roles in determining the social costs associated with the bargaining outcome. Finally, we show that short-term bargaining agreements are unlikely to succeed in our application, which suggests that there may be a role for a higher government to facilitate long-term bargaining agreements.

\subsection{Theoretical Framework}

Suppose there are two municipalities, one of which is infested with an invasive species and one of which is uninfested. With the exception of this initial state, the municipalities are identical. ${ }^{4}$ The uninfested municipality faces a positive probability that it will become infested by an invasive species in each time period $t .{ }^{5}$ Denote the probability of spread from the infested to the uninfested municipality as $P(t)$. The probability of spread may be a function of the size of the invasive species population as well as the species' behavioral patterns and the characteristics and availability of relevant host species (Cobourn et al. 2011). The set of state variables that govern the probability of spread will differ with the invasive species and host(s) under consideration. Using the probability of spread as the model's state

\footnotetext{
4 This assumption is simply one of convenience and implies that $V(0)$, the net benefit to a municipality when it is infested but no transfer payment is received, is identical across municipalities. The model can be extended to reflect differences in tree cover and costs of control by differentiating this term across municipalities. This change affects the solution to the bargaining problem only by altering the disagreement outcomes in Eqs. (4)-(5), which affects the relative Hamiltonian weights in Eq. (12). The comparative insights developed later would not be affected by this additional complexity.

5 In the case of emerald ash borer, the probability of spread is driven by the ovipositional preferences of the female beetle, which are proportional to the size of the pest population, the density of ash trees, and the prevalence of stressed, or vulnerable, ash trees (Mercader et al. 2011).
} 
variable allows us to accommodate these differences across applications within a general framework. ${ }^{6}$

The instantaneous change in the probability of spread at any point in time is given by the equation of motion: $\dot{P}(t)=f(P(t))$. The function $f(\cdot)$ describes the rate of growth in the probability of spread as a function of the probability of spread at time $t, P(t)$, which summarizes all prior control decisions. ${ }^{7}$ We assume $f(\cdot)$ is increasing and may be either concave or convex in $P(t)$.

The uninfested municipality may have an incentive to bargain through sharing in the control costs of the infested municipality. By doing so, the uninfested municipality can reduce the probability that the invasive species will spread during a post-agreement period of higher control. We model this cost share as a transfer payment in each period, $\tau(t)$, made from the uninfested to the infested municipality. ${ }^{8}$ The transfer payment reduces the growth in the probability of spread in proportion to an exogenous and species-specific constant, $\delta: 9,10$

$$
\dot{P}(t)=f(P(t))-\delta \tau(t)
$$

The transfer payment in each period is non-negative, i.e. $\tau(t) \geq 0$, where a transfer payment of zero reflects the possibility that it may not be optimal to engage in cooperation in every period in the problem, even if it is optimal to cooperate at some point over the full planning horizon.

Should a bargaining agreement occur, the infested municipality earns net benefits that depend on the transfer payment, denoted $V(\tau(t))$, plus the transfer payment itself in each

6 If the path of spread was driven solely by, for example, the size of the pest population, $N(t)$, it would be a straightforward extension of our model to specify population size as the model's state variable using a probability of spread function given by $P(N(t))$. Other features of the model, such as the damage caused by the pest, could also be modified to depend on $N(t)$.

7 This growth function is a reduced form representation of the mechanics of the invasion that offers the benefit of generality. For a specific application, spread may be modeled explicitly to reflect case-specific dynamics of the pest and the host, as well as spatial characteristics of the problem, such as the distance between the two municipalities.

8 We require commitment to exist here on the part of both municipalities. Not only is this easy to envision if municipalities are governments and transfers happen through administrative and legal procedures, but commitment has also been a common assumption in the bargaining literature. We also recognize that it may be the case that a transfer payment of the type proposed here would require a vote by inhabitants of the uninfested municipality, who may have different incentives to bargain than the government itself. In this case, the government is acting as a first-best planner (for its own citizens) and reduces the transaction costs of bargaining so that an agreement can be reached in the Coase spirit.

9 It is possible that in some cases, the effectiveness of control, $\delta$, is a declining function of the probability of spread, $P(t)$. We do not model $\delta$ as endogenous in this study because doing so renders the theoretical model and our simulation approach intractable, and because it would require considerable data to calibrate the effect beyond some arbitrary assumption. Instead, we conduct a numerical sensitivity analysis in which we consider high and low values for $\delta$. A comparison of the results between these two cases captures the intuition behind the effect of a decrease in $\delta$ as $P(t)$ declines, ceteris paribus.

10 Of all parameters in the model, this parameter, which is a technical coefficient that captures the relationship between a dollar spent on control and a reduction in the probability of spread, may be the one with the most uncertainty given that data concerning controls and invasive species population changes are not generally available. While it is not difficult to add uncertainty in this parameter, this would add little insight because this uncertainty would be common to both municipalities, and because spread is already probabilistic and is the most important aspect of the problem. Uncertain efficacy would simply be reflected in the already uncertain probability of spread. 
period. The present value of net benefits for the infested municipality over any finite time horizon, $T$, is: ${ }^{11}$

$$
J_{I}(\tau)=\int_{0}^{T} e^{-\rho t}\{V(\tau(t))+\tau(t)\} d t
$$

where $\rho$ is the discount rate. The transfer payment compensates the infested municipality for undertaking greater control than it would in the absence of such a payment. Increased control is costly to the infested municipality not only because it involves an increase in the cost of control but also because it involves removal of the host plant species (e.g. ornamental trees or plants), which reduces the non-market benefits derived from the host species within the infested municipality. The net benefit function for the infested municipality (excluding the transfer payment) captures both the increase in control costs as well as the loss in non-market benefits from the host. This function is defined as: $V(\tau(t))=B(\tau(t))-C(\tau(t))$, where $B(\cdot)$ is the non-market benefit associated with host plant species and $C(\cdot)$ is the cost of control. In this specification, the transfer payment can be thought of as an index variable describing the intensity of controls and control costs undertaken by the infested municipality at time $t .{ }^{12}$ The non-market benefit function is decreasing and concave in the transfer payment and the cost of control function is increasing and convex in the transfer payment. These assumptions imply that $V(\cdot)$ is a decreasing and concave function of the transfer payment, i.e., as host plants are removed, their marginal value increases due to relative scarcity.

While the benefits earned by the infested municipality are a known function of the transfer payment, the uninfested municipality's future net benefits are not known because they depend on the probability of spread through time. ${ }^{13}$ Should a bargaining agreement occur, the present value of expected net benefits for the uninfested municipality is: ${ }^{14}$

$$
J_{U}(\tau)=\int_{0}^{T} e^{-\rho t}\{[1-P(t)] \bar{V}+P(t) V(0)-\tau(t)\} d t
$$

\footnotetext{
${ }^{11}$ An infinite time horizon is unlikely given that the period of cooperation in the form of transfers would likely be limited by administrative mechanisms in each municipality.

12 We assume that there is a close correspondence between the level of control and the transfer payment, and thus for simplicity we write net benefits as a function only of the transfer payment. For example, we could write the level of control as a function of the transfer payment, $e(\tau(t))$, where $e^{\prime}>0$. The net benefit function could then be written as $V(e(\tau(t)))$. Doing so complicates the notation without altering the results of the theoretical model.

13 Although a closed-loop modeling approach could be used to allow renegotiation of the transfer payment in each period in response to updated information about whether the invasive species has spread, we use an openloop approach in this analysis for several reasons. First, renegotiating a new transfer payment in each period for two municipalities likely involves high transactions costs. The results of our numerical simulation demonstrate that in many cases, such short-term agreements are unlikely to satisfy bargaining incentive constraints for both municipalities even without accounting for these transactions costs, so a longer-term agreement (modeled in the manner we choose) may be more viable in cases like that of the emerald ash borer. Second, because it is difficult to detect the arrival of emerald ash borer within the first 3-4 years after infestation, an annual reassessment of whether the pest has spread would be difficult to implement in practice. Finally, an open-loop formulation is appealing in terms of its ability to yield analytical insight into the bargaining transfer paths as is illustrated below.

${ }^{14}$ Because $P(t)$ incorporates all pest control decisions prior to period $t$, the welfare function in period $t$ also depends on all prior treatment control decisions.
} 
The expected net benefits earned by the uninfested municipality, excluding the transfer payment, are given by $[1-P(t)] \bar{V}+P(t) V(0) .{ }^{15}$ This expression captures how bargaining affects the uninfested municipality by affecting the probability of the spread of the invasive species and hence the expected damages from infestation. The first term in this expression captures the net benefits if the invasive species does not spread in period $t$; the second term captures the net benefits if the species spreads with probability $P(t)$.

During periods in which the uninfested municipality remains uninfested, its net benefits are assumed given by $\bar{V}$, which is the maximized level of net benefits accruing already to the uninfested municipality in each time period. ${ }^{16} \bar{V}$ thus forms an upper bound on the level of net benefits derived from the host plant species. If the uninfested municipality becomes infested, it chooses control to maximize its own net benefits. We denote this maximized level of net benefits as $V(0)$, which is equivalent to the net benefits for the infested municipality when there is no transfer payment. ${ }^{17}$ Infestation is costly for the uninfested municipality because it results in the loss of non-market benefits from the host plant species and/or because it requires costly control. This implies that $V(0)<\bar{V}$. There is no technological progress over time concerning control, which is consistent with the time horizon under which bargaining would likely occur in practice (and as we will show is consistent with our simulation results). Thus, $V(0)$ is exogenous and time invariant in the model.

In bargaining settings, the disagreement (or threat) outcome becomes relevant to the solution. This outcome results in the net benefits each municipality receives if no agreement is reached. In our model, the disagreement outcome is simply the stream of net benefits each municipality would receive in the absence of an agreed-upon transfer payment. ${ }^{18}$ When there is no bargaining, the infested municipality is assumed to choose control to maximize its own net benefits in each period, given by $V(0)$ :

$$
d_{I}=\int_{0}^{T} e^{-\rho t} V(0) d t
$$

The uninfested municipality faces expected net benefits in each period that depend on the probability of spread when there is no transfer payment, i.e. under lower control used by the infested municipality. To distinguish the probability of spread with and without an agreement, we denote the probability of spread without an agreement as $\left.P(t)\right|_{\tau=0}$. The time path for $\left.P(t)\right|_{\tau=0}$ is given by Eq. (1) when $\tau(t)=0$ for all $t \in[0, T]$. Given this path, the expected net benefits to the uninfested municipality in period $t$ are $\left[1-\left.P(t)\right|_{\tau=0}\right] \bar{V}+\left.P(t)\right|_{\tau=0} V(0)$. The disagreement outcome for the uninfested municipality is therefore given by:

\footnotetext{
15 The path of transfer payments in (3) is outside of the expectation. This is reasonable in our empirical application given that it is difficult to detect whether the pest has spread over the relevant time horizon for a bargaining agreement (on the order of several years). Incorporating the transfer payment into the expectation here complicates the analytical expressions for the path of transfer payments under bargaining and the first-best outcomes. The difference in these two transfer payment paths, given by (18), remains analytically tractable but its increased complexity yields little additional insight into the problem.

16 For simplicity $\bar{V}$ is not time dependent. There is time dependence through many other channels that can affect the outcome of our bargaining game. The disagreement outcomes in (4) and (5) are in fact time dependent and will therefore change over time. Moreover, the agreement region of the problem, given in (7), is also time dependent. Including an additional time dependence through $\bar{V}$ would complicate the problem, while adding little in terms of the intuition derived from the model.

17 We do not consider the case in which two infested municipalities share in control costs. Because the municipalities are identical in all ways except for their initial state, they earn the same level of net benefits when they are infested.

18 The disagreement outcome here is a corner solution in our model (see also Amacher and Malik 1998). It is in effect a pure free-riding solution for the uninfested municipality, which by doing nothing waits as long as possible before spending the cost of control.
} 


$$
d_{U}=\int_{0}^{T} e^{-\rho t}\left\{\left[1-\left.P(t)\right|_{\tau=0}\right] \bar{V}+\left.P(t)\right|_{\tau=0} V(0)\right\} d t
$$

\subsubsection{Region of Bargaining Agreement}

Incentives to bargain must exist for each municipality in order to reach any agreement. For the municipalities to reach a bargaining agreement, there must exist a path of transfer payments such that $J_{U}(\tau)>d_{U}$ and $J_{I}(\tau)>d_{I}$. Combining these two expressions and using Eqs. (2)-(5) yields the following bounds on the present value of the stream of transfer payments over the problem's time horizon:

$$
\int_{0}^{T} e^{-\rho t}\{V(0)-V(\tau(t))\} d t<\int_{0}^{T} e^{-\rho t} \tau(t) d t<\int_{0}^{T} e^{-\rho t}\left\{\left(\left.P(t)\right|_{\tau=0}-P(t)\right)(\bar{V}-V(0))\right\} d t
$$

For the infested municipality, the present value of the stream of transfer payments must exceed the present value of the stream of losses that the municipality experiences as a result of undertaking greater control activities. Recall that the infested municipality earns net benefits $V(0)$ in period $t$ if no agreement is reached and net benefits of $V(\tau(t))$ in the event of an agreement. The left-hand inequality in (6) reflects that the infested municipality has an incentive to bargain whenever the present value of the stream of transfer payments exceeds the present value of the difference in these two net benefit functions, where $V(0)-V(\tau(t)) \geq 0$ because $V$ is decreasing in $\tau$.

For the uninfested municipality, the present value of the stream of transfer payments must not exceed the present value of the stream of gains that arise due to a decrease in the probability that the invasive species spreads. The uninfested municipality earns net benefits $\left[1-\left.P(t)\right|_{\tau=0}\right] \bar{V}+\left.P(t)\right|_{\tau=0} V(0)$ in period $t$ if no agreement is reached and net benefits of $[1-P(t)] \bar{V}+P(t) V(0)$ in the event of an agreement. The right-hand inequality in (6) reflects that the uninfested municipality has an incentive to bargain whenever the present value of the stream of transfer payments does not exceed the present value of the difference in these two net benefit functions, where $\left(\left.P(t)\right|_{\tau=0}-P(t)\right)(\bar{V}-V(0)) \geq 0$ because $P(t) \leq P(t) \leq\left. P(t)\right|_{\tau=0}$ and $V(0)<\bar{V}$. The first parenthetical term on the right-hand side captures the change in the probability of spread when the municipalities come to an agreement. The second parenthetical term on the left-hand side captures the maximum loss in net benefits due to the arrival of the invasive species in the uninfested municipality.

The dynamic condition in (6) ensures that over the duration of the problem each party gains from bargaining relative to the disagreement outcome. It need not be the case that each party gains in every period from bargaining relative to the disagreement outcome. However, considering the static bargaining region for the problem allows us to derive intuition about how the time horizon of a bargaining problem may affect the bargaining outcome. If the optimal path of transfer payments involves losses to one party early in the problem's time frame, but those losses are offset (in present value terms) by later benefits, there may be a role for a higher authority to play in facilitating multi-period bargaining between municipalities. Conversely, if it is not possible for the municipalities to engage in a bargaining agreement that lasts for more than a single period, the bargaining outcome may result in greater social costs than a longer-term agreement.

For a single time period, both municipalities have an incentive to bargain when:

$$
V(0)-V(\tau(t)) \leq \tau(t) \leq\left(\left.P(t)\right|_{\tau=0}-P(t)\right)(\bar{V}-V(0)) .
$$

For the municipalities to agree upon a transfer payment, it must be the case that the expected gain to the uninfested municipality exceeds the loss in net benefits to the infested municipality 
from undertaking greater control. Expression (7) defines the bargaining contract curve, or region of agreement, for the two municipalities. A similar representation for a different, static bargaining problem is considered by Amacher and Malik (1998). Our case is considerably different than theirs because the contract curve in (7) is time dependent. The region of agreement in (7) depends on the path of transfer payments and the probability of spread for the invasive species, which are linked through Eq. (1). Clearly, the size of the agreement region, and hence whether or not a bargaining agreement is reached, is specific to each invasive species due to differences in spread rates and the damage inflicted by the species.

Although it is not possible to solve explicitly for bounds on the transfer payment without specifying functional forms for $V(\tau(\tau))$ and $f(P(\tau))$, (7) yields some interesting intuition. The range of transfer payments that satisfy (7) increases whenever the potential losses to the uninfested municipality from infestation increase, i.e. $\bar{V}$ increases relative to $V(0)$. Conversely, factors that reduce the range of transfer payments satisfying (7) include an increase in net benefits for the infested municipality without bargaining, $V(0)$, or a reduction in the probability of spread without bargaining, $\left.P(t)\right|_{\tau=0}$.

\subsubsection{Nash Bargaining}

The Nash bargaining solution is a transfer payment stream that maximizes the product of the net gains from bargaining (Nash 1950):

$$
\max _{\tau(t)}\left(J_{I}(\tau)-d_{I}\right)^{\gamma_{I}}\left(J_{U}(\tau)-d_{U}\right)^{\gamma_{U}},
$$

where $J_{\mathrm{I}}(\tau), J_{U}(\tau), d_{I}$, and $d_{U}$ are as defined in Eqs. (2)-(5). Expression (8) is maximized subject to Eq. (1) and initial condition $P(0)=P_{0}$. The exponents $\gamma_{I}$ and $\gamma_{U}$ capture the potential for the municipalities to possess differing levels of bargaining power. These parameters satisfy the restrictions: $0 \leq \gamma_{I} \leq 1,0 \leq \gamma_{U} \leq 1$, and $\gamma_{I}+\gamma_{U}=1$. Differences in bargaining power reflect which municipality's relative gains matter more to the agreement. These coefficients therefore affect the position of the agreed-upon transfer payment within the agreement region described by (7). For example, should the uninfested municipality hold all of the bargaining power, then $\gamma_{U}=1$, the net gains to bargaining for the infested municipality drop out of (8), and the optimal transfer payment maximizes only the uninfested municipality's net gains. We will return to the influence of relative bargaining power on the bargaining outcome in the numerical analysis. ${ }^{19}$

The form of the bargaining problem in (8) is not a mathematically convenient expression to solve for the dynamic path of transfer payments should an agreement occur. Instead of using this nonlinear expression, we use the results of Ehtamo et al. (1988), who prove that the problem in (8) can be written without loss as a current value Hamiltonian of the form: $H\left(P, \tau, \lambda, \mu_{I}, \mu_{U}, t\right)=\mu_{I}\left(V(\tau(t))+\tau(t)-d_{I}\right)+\mu_{U}([1-P(t)] \bar{V}+P(t) V(0)-$ $\left.\tau(t)-d_{U}\right)+\lambda(t)[f(P(t))-\delta \tau(t)]$, where $\mu_{I}$ and $\mu_{U}$ are weights for the infested and uninfested municipalities, respectively. These weights are defined as $\mu_{I}=\gamma_{I}\left(J_{I}\left(\tau(t)^{B}\right)-\right.$ $\left.d_{I}\right)^{\gamma_{I}-1}\left(J_{U}\left(\tau(t)^{B}\right)-d_{U}\right)^{\gamma_{U}}$ and $\mu_{U}=\gamma_{U}\left(J_{I}\left(\tau(t)^{B}\right)-d_{I}\right)^{\gamma_{I}}\left(J_{U}\left(\tau(t)^{B}\right)-d_{U}\right)^{\gamma_{U}-1}$, where $\tau(t)^{B}$ denotes the path of transfer payments that solves (8).

19 We might expect that the bargaining power held by the uninfested municipality would be relatively low if there is a high probability of spread from areas other than the adjacent infested municipality. For emerald ash borer, however, there is a small probability that the pest will spread to the uninfested municipality due to long-distance transport, but that probability is minor compared to the probability of spread from the adjacent municipality. As demonstrated by Kovacs et al. (2010), EAB tends to spread in a way that is consistent with an invasion front, rather than a more scattered pattern of spread. 
These weights are a function of the relative net gains from bargaining for each municipality and the bargaining power coefficients. To see how the relative net gains from bargaining for each municipality influence the Hamiltonian weights, consider the case in which the bargaining power coefficients are equal, i.e. $\gamma_{I}=\gamma_{U}=0.5$. As the net gains from bargaining for the uninfested municipality increase relative to those of the infested municipality, $\mu_{U}$ decreases while $\mu_{I}$ increases. Intuitively, the municipality that stands to gain more from an agreement is at a bargaining disadvantage relative to the municipality that stands to gain less from an agreement. The weighting scheme reduces the weight for the municipality with greater net gains from bargaining, skewing the optimal bargaining outcome in favor of the municipality with lower net gains. Increasing the bargaining power coefficient for the municipality that stands to gain more from agreement counteracts this effect.

Per Ehtamo et al. (1988), Eq. (1) along with the following conditions are necessary and sufficient for problem (8) under our standard convexity assumptions: ${ }^{20}$

$$
\begin{gathered}
\frac{\partial H}{\partial \tau}=\mu_{I}\left(V^{\prime}(\tau(t))+1\right)-\mu_{U}-\delta \lambda(t)=0, \\
-\frac{\partial H}{\partial P}=\mu_{U}(\bar{V}-V(0))-\lambda(t) f^{\prime}(P(t))=\dot{\lambda}(t)-\rho \lambda(t), \\
\lambda(T)=0 .
\end{gathered}
$$

Equations (9) and (10) describe the optimal paths for the control and the state variables. Equation (11) is a transversality condition that defines the optimal ending point for the path of the spread probability, which occurs when the shadow value of additional transfers, measured in terms of a decrease in the probability of spread, equals zero.

Combining (9) and (10) yields the optimal path for the transfer payment under Nash bargaining:

$$
\dot{\tau}(t)^{B}=\left(\rho-f^{\prime}\right) \frac{V^{\prime}}{V^{\prime \prime}}+\frac{\mu_{U}}{\mu_{I}}\left[\frac{\delta(\bar{V}-V(0))}{V^{\prime \prime}}\right]+\frac{\left(\mu_{I}-\mu_{U}\right)}{\mu_{I}}\left[\frac{\left(\rho-f^{\prime}\right)}{V^{\prime \prime}}\right] .
$$

As described in Table 1, the sign of (12) is ambiguous. Whether the path of transfer payments in the Nash bargaining solution increases or decreases over time depends on the relative magnitudes of all three terms on the right-hand side of expression (12), including the signs of the expressions $\rho-f^{\prime}$ and $\mu_{I}-\mu_{U}$. Intuitively, the term $\rho-f^{\prime}$ can be thought of as an effective discount rate. The term $\mu_{I}-\mu_{U}$ may be interpreted by examining the relative bargaining weights for the municipalities. Using the definitions for each weight, $\mu_{I}>\mu_{U}$ implies that $\gamma_{I} / \gamma_{U}>\left(J_{I}\left(\tau(t)^{B}\right)-d_{I}\right) /\left(J_{U}\left(\tau(t)^{B}\right)-d_{U}\right)$, i.e. the infested municipality's relative bargaining weight exceeds their relative net gains from bargaining.

While the sign of (12) is ambiguous, the path of transfer payments is either monotonically increasing or decreasing depending on the problem's parameters. This implies that the transfer payment path will cross one of the bounds in expression (7) at most once, i.e. it is not possible for the path of transfer payments to cross in and out of the range of feasible bargaining outcomes multiple times.

20 Specifically, these results require that the constraint set is convex and the objective functionals for both municipalities are concave over the constraint set. These assumptions hold given our assumptions about the shapes of $f(P(t))$ and $V(\tau(t))$. 
Table 1 Transfer payment paths and comparative statics results with different parameters
$\dot{\tau}(t)^{B}$ denotes the time derivative of the path of transfer payments that solves the Nash bargaining problem; $\dot{\tau}(t)^{S P}$ denotes the time derivative of the path of transfer payments that solves the first-best problem

\begin{tabular}{lll}
\hline & $\mu_{I}<\mu_{U}$ & $\mu_{I}>\mu_{U}$ \\
\hline Sign of $\dot{\tau}(t)^{B}$ & & \\
$\rho<f^{\prime}$ & - & \pm \\
$\rho>f^{\prime}$ & \pm & \pm \\
Sign of $\dot{\tau}(t)^{S P}$ & & - \\
$\rho<f^{\prime}$ & - & \pm \\
$\rho>f^{\prime}$ & \pm & \\
Sign of $\dot{\tau}(t)^{S P}-\dot{\tau}(t)^{B}$ & & - \\
$\rho<f^{\prime}$ & + & \pm \\
$\rho>f^{\prime}$ & \pm & - \\
Sign of $d\left(\dot{\tau}(t)^{S P}-\dot{\tau}(t)^{B}\right) / d X$ & & - \\
$X=\bar{V}-V(0)$ & $\mathrm{v}$ & - \\
$X=f^{\prime}$ & + & + \\
$X=\delta$ & + & \\
$X=\rho$ & - & \\
\hline
\end{tabular}

\subsubsection{First-Best Problem}

A social planner would choose a transfer payment through time to maximize the sum of net benefits to both municipalities. The social planner chooses the transfer payment to solve the problem:

$$
\max _{\tau(t)}\left(J_{I}(\tau)+J_{U}(\tau)\right)
$$

subject to (1) and initial condition $P(0)=P_{0}$. The Hamiltonian for problem (13) is: $H(P, \tau, \lambda, t)=(V(\tau(t))+\tau(t))+([1-P(t)] \bar{V}+P(t) V(0)-\tau(t))+\lambda(t)[f(P(t))-\delta \tau(t)]$. Equation (1) along with the following conditions is necessary and sufficient for problem (13):

$$
\begin{gathered}
\frac{\partial H}{\partial \tau}=V^{\prime}(\tau(t))-\delta \lambda(t)=0 \\
-\frac{\partial H}{\partial P}=(\bar{V}-V(0))-\lambda(t) f^{\prime}(P(t))=\dot{\lambda}(t)-\rho \lambda(t) \\
\lambda(T)=0
\end{gathered}
$$

Combining (14) and (15) yields the optimal path for the social planner's transfer payment:

$$
\dot{\tau}(t)^{S P}=\left(\rho-f^{\prime}\right) \frac{V^{\prime}}{V^{\prime \prime}}+\delta \frac{(\bar{V}-V(0))}{V^{\prime \prime}}
$$

As is the case for the Nash bargaining path in (12), whether the first-best path of transfer payments is decreasing or increasing over time depends on the magnitudes of the problem's parameters, especially the difference between the discount rate and the rate of growth in the probability of spread, $\rho-f^{\prime}$. If the rate of growth in the probability of spread exceeds the discount rate, the path of transfer payments decreases over time. Otherwise, the direction of the path is ambiguous and depends on the relative magnitude of the first and second terms on the right-hand side of (17). 


\subsubsection{Comparison of First-Best and Nash Bargaining Paths}

Comparing (17) with (12) reveals that the path for transfer payments under Nash bargaining differs considerably from the social planner's path. Specifically, the second term on the right-hand side of (12) is weighted by the ratio of the Hamiltonian weights, $\mu_{U} / \mu_{I}$, and the right-hand side of (12) includes an additional, third term not included in (17). We can summarize the difference in the social planner's and Nash bargaining paths as:

$$
\dot{\tau}(t)^{S P}-\dot{\tau}(t)^{B}=\frac{\left(\mu_{I}-\mu_{U}\right)}{\mu_{I}}\left[\frac{\delta(\bar{V}-V(0))-\left(\rho-f^{\prime}\right)}{V^{\prime \prime}}\right] .
$$

When $\mu_{U}=\mu_{I}$, the paths for the social planner and Nash bargaining problems are identical. This requires more than equal bargaining power between the municipalities: it requires that the ratio of the bargaining power coefficients to the optimized net gains from bargaining are equal across municipalities, i.e. $\gamma_{I} /\left(J_{I}(\tau(t))-d_{I}\right)=\gamma_{U} /\left(J_{U}(\tau(t))-d_{U}\right)$. In general, it will likely not be the case that this condition holds. When this condition does not hold, the difference in the two paths depends on the difference in the bargaining weights, $\mu_{I}-\mu_{U}$, along with several other important parameters. In particular, the difference $\rho-f^{\prime}$ plays a critical role in the problem.

Table 1 summarizes the direction of the difference between the socially optimal and Nash bargaining transfer payment paths for all cases describing the signs of $\rho-f^{\prime}$ and $\mu_{I}-\mu_{U}$. For example, if $\rho<f^{\prime}$, the bracketed term on the right-hand side of (18) is positive. In this case, the difference between the bargaining weights, $\mu_{I}-\mu_{U}$ (or equivalently the relative bargaining weight of the infested municipality), determines whether the social planner's path changes more quickly than that of the Nash bargaining path. If the relative bargaining weight of the infested municipality exceeds their relative net gains from bargaining $\left(\mu_{I}<\mu_{U}\right)$, then $\dot{\tau}(t)^{S P}>\dot{\tau}(t)^{B}$. In this case, the bargaining outcome results in a transfer payment path that is spread more evenly over time than is socially optimal. Conversely, when the relative bargaining weight of the infested municipality falls short of their relative net gains from bargaining $\left(\mu_{I}>\mu_{U}\right)$, the Nash bargaining outcome results in a transfer payment path that grows or declines more quickly than the first-best path. In contrast, if $\rho>f$, the second, bracketed term in (18) is ambiguous in sign.

Regardless of whether the direction of the difference between the two paths is positive or negative, (18) illustrates that the magnitude of the difference between the two paths depends on several key parameters in the problem. Specifically, these include the rate at which the probability of spread increases $\left(f^{\prime}\right)$, the efficacy of the transfer payment in slowing the spread of the invasive species $(\delta)$, and the loss in net benefits to a municipality when it becomes infested $(\bar{V}-V(0))$. As illustrated in Table 1, the effect of a marginal change in each of these parameters on the difference between the first-best and bargaining paths depends on the sign of the difference between the bargaining weights, $\mu_{I}-\mu_{U}$. An increase in each of these parameters leads to a greater divergence between the first-best and bargaining paths when $\mu_{I}<\mu_{U}$ and a smaller divergence when $\mu_{I}>\mu_{U}$. These changes are driven by competing effects that arise due to the effect of discounting on the costs of control (direct costs plus lost nonmarket benefits) and changes over time in the expected damages of infestation that are driven by changes in the probability of spread.

The theoretical model presented in this section is general enough to apply to any situation where there is scope for cooperation across space to limit the spread of an invasive species and where control is costly in terms of direct inputs and/or lost nonmarket values from removal of a host plant species. Our theoretical results show that there will be important differences in the bargaining and first-best outcomes, and we have found that these differences are sensitive 
to several key parameters such as the relative bargaining power of parties involved as well as biological features of the invasive species in question. Our results also indicate that the path of transfer payments in the bargaining outcome relative to that of the first-best outcome changes as a result of competing effects that unfold over time in this dynamic problem. These tradeoffs depend on the relative magnitudes of a number of parameters in the problem and as a result are an empirical question. In the next section, we apply our theoretical framework to consider these tradeoffs and bargaining outcomes in the context of an empirical application.

\subsection{Application to Emerald Ash Borer in the Twin Cities}

In this section, we examine the results of our theoretical model with a specific example currently important in many regions of the U.S. and where data exists with which we can calibrate our model - the case of emerald ash borer (EAB) (Agrilus planipennis Fairmaire) in the Twin Cities (Minneapolis and St. Paul, Minnesota). We use a numerical simulation to examine the outcomes, in terms of social cost, of an uncoordinated, privately optimal outcome; the Nash bargaining outcome; and the first-best, social planner's outcome, which represents the outcome under perfect coordination. We also present the results for a range of values in the parameters identified as important in the theoretical framework. We find that application of our model leads to many interesting implications for how agreements can be reached to stem the spread of any invasive species.

The rapid rise of the EAB, native to Asia, provides a perfect setting to examine our problem. This beetle feeds on the inner bark (phloem) of the common ornamental North American ash tree (Fraxinus spp.). EAB was first discovered in North America in June of 2002 near Detroit, MI and Windsor, Ontario, Canada. By 2009, EAB had spread to 10 U.S. states and two Canadian provinces and killed an estimated 53 million ash trees (Kovacs et al. 2010). The beetle feeds on all ash species in North America, but demonstrates a preference for the most commonly planted green ash (F. pennsylvanica) and black ash ( $F$. nigra).

Each year, female beetles lay eggs on the exterior bark of trees. Larvae hatch and bore into the tree, feeding on the phloem and cambium throughout the summer and early fall. Larvae over-winter in the external bark, pupating in April or May of the following spring. Adult EAB emerge from trees in late May through early August. The cycle is usually repeated for one generation per year, though sometimes larvae may take longer to develop in relatively healthy ash trees or in colder environments. Damage to ash trees is caused as developing larvae tunnel through a tree's phloem, girdling the tree and disrupting the flow of water and nutrients. Within 2-4 years of initial infestation, a tree exhibits the symptoms of EAB infestation, including canopy thinning, branch dieback, and death. Because damage by the $\mathrm{EAB}$ is predominantly internal, infestation is rarely detected before the tree exhibits these external signs.

There is strong evidence to suggest that the rate of spread of EAB depends on larval density, which is a function of host tree density and pest population size (Mercader et al. 2011). The spread of the pest is entirely driven by the ovipositional preferences of adult female beetles that demonstrate an ability to fly up to $5 \mathrm{~km}$ in search of host trees though females are attracted to areas of high ash tree density. Therefore, in areas with continuous forest cover, such as greenways and open space, the rate of spread is higher than in area with discontinuous or dispersed host tree coverage. Long-distance dispersal tends to result primarily from human transport of infested nursery trees or firewood, though the probability of spread through this mechanism is small relative to the probability of spread from an adjacent infested area (Kovacs et al. 2010). 
To date, control to prevent the spread of EAB has primarily taken one of two forms. The first involves the removal of all or a subset of ash trees; the second involves the application of the systemic insecticide emamectin benzoate aimed at preserving as many standing trees as possible. Tree removals are more costly than insecticide use due to the direct costs of tree removal and replacement as well as the loss of non-market benefits as mature host trees are removed. Insecticides are applied periodically as soil injections or drenches, trunk injections, lower trunk sprays, or protective cover sprays. Trunk injections have proven to be highly effective, attaining a reduction in beetle larvae exceeding $99 \%$ for 2 years, even in areas with high pest pressure (Herms et al. 2014). ${ }^{21}$

In 2009-2010, EAB was first detected in the adjacent Twin Cities of Minneapolis and St. Paul, Minnesota. Within these cities, ash trees form an important component of the urban canopy. Green ash and white ash (F. Americana) are used widely to line streets and other public spaces. More than 40,000 ash trees in the city of Minneapolis are located on public property; another 200,000 are located on private property (Minneapolis Park and Recreation Board 2014). St. Paul reports that 20,000 ash trees are located on city boulevards alone (St. Paul Parks and Recreation 2015). Though the cities of Minneapolis and St. Paul are already infested with EAB, EAB has not yet been detected in many of the surrounding municipalities, such as Edina and Golden Valley. Kovacs et al. (2014) project that EAB will spread to nearby municipalities within the next several years.

Minneapolis and St. Paul have chosen differing approaches for controlling infestation of public ash trees. The Minneapolis Park and Recreation Board initiated a campaign in June of 2014 to preemptively remove and replace all public ash trees over the course of 8 years. The removal is phased such that approximately 5000 ash trees will be removed each year, with no more than $20 \%$ of the tree canopy on a single block removed each season. The removal and replacement plan is funded by a $\$ 1.2$ million annual levy, which was first passed in 2013. The levy must be passed each year for the plan to continue. Minneapolis has chosen not to use insecticides to combat the spread of EAB because of concern about the unknown environmental impacts of systemic insecticides, including the effects on pollinators and water quality.

In contrast, the City of St. Paul has elected to preserve standing ash trees by incorporating the use of the systemic insecticide into a multifaceted approach to control. To limit beetle populations, the city treats high-value (large) public trees that are near an infested area and in good health by administering trunk injections of emamectin benzoate. However, these insecticide treatments are not viewed by the city as a means of preserving ash trees in the long run (City of St. Paul 2014). The city also runs a "structured removal" program: instead of phasing out all public ash trees, St. Paul preemptively removes on a rolling basis public ash trees that have been weakened by other factors and are therefore likely to be more susceptible to EAB infestation (St. Paul Parks and Recreation 2015).

\subsubsection{Numerical Simulation Model}

Using data that exists from the EAB infestation in the Twin Cities, we use a numerical simulation model to examine the role that a bargaining outcome could play in reducing social costs relative to the uncoordinated, privately optimal outcome. Here, we ask the question: to what extent could bargaining lower social costs under the assumption that one city is infested

21 Insecticides are most effective when their use is begun prior to infestation, though difficulty detecting adult beetles and early stages of infestation makes it hard to identify when to start treatments. Insecticide treatment is recommended if a tree is within 15-24 km of a known EAB infestation (Herms et al. 2014). 
and the other is not? The results from the simulation provide insight concerning how close the bargaining outcome is to the first-best strategy employed by a social planner. The simulation also serves to develop intuition for the theoretical model and provides insight into the relative importance of the model's parameters.

The Twin Cities are an advantageous case study because there are sufficient data on the spread of EAB between St. Paul and Minneapolis to calibrate the simulation model. The EAB infestation originated in St. Paul while Minneapolis remained uninfested for a period, during which the control strategies pursued by the cities were best described as an uncoordinated outcome. Our simulation analysis is an ex post counterfactual in which we ask how cooperative bargaining might have performed after St. Paul became infested but before EAB spread to Minneapolis. Although both St. Paul and Minneapolis are now infested, our bilateral bargaining model continues to be relevant as EAB spreads between surrounding municipalities. For example, the City of Eagan is currently infested, but the adjacent City of Burnsville is uninfested. These neighboring communities are likely to share information, knowledge, and resources in an effort to slow EAB spread and forestall the loss of their urban ash canopy. In this setting, the potential for bilateral bargaining as EAB spreads between municipalities is consistent with the type of chained, bilateral agreements likely to arise in the presence of transactions costs, as described by Wilen (2007).

The parameter values used in the simulation model are listed in Table 2. These are constructed based on data collected as part of current pest monitoring and control efforts in both cities. For the simulation, we assume that each municipality contains 20,000 ash trees that are in the public domain. When ash trees are uninfested, previous work has shown that each tree generates annualized non-market benefits of $\$ 94$ (Sander et al. 2010). ${ }^{22}$ The maximum level of non-market benefits that can be earned by a municipality when it remains uninfested, $\bar{V}$, are $\$ 1.88$ million per year. When a municipality becomes infested but there is no bargaining agreement, it is assumed to spend $\$ 1$ million per year on control, which may include a combination of insecticide treatments and the removal and replacement of ash trees. This cost is similar in magnitude to current annual expenditures cited by Minneapolis and St. Paul (Melo 2014; Minneapolis Park and Recreation Board 2014). Absent a bargaining agreement, the net benefits earned by each municipality when infested, $V(0)$, are therefore $\$ 0.88$ million per year.

Given that no bargaining solution has been observed between Minneapolis and St. Paul, little information is available on the way in which a transfer payment would affect the net benefit function for the infested municipality. We assume this net benefit function is quadratic in the transfer payment, i.e. $V(\tau(t))=V(0)+b \tau(t)+c \tau(t)^{2}$, where $b, c<0$. The maximum net benefits that can be earned by the infested municipality are those earned in the absence of a transfer payment, $V(0)$. A positive transfer payment from the uninfested to the infested municipality reduces net benefits earned by the latter because it requires the removal of trees and more costly control than the municipality would undertake in the absence of a bargaining agreement. The transfer payment must compensate the infested municipality for these losses. We calibrate the parameters of the net benefit function based on the removal and replacement cost of a tree at an average of $\$ 818$ in the region (McCullough and Mercader 2012).

\footnotetext{
22 Sander et al. (2010) find that the average homeowner in Dakota and Ramsey counties in Minnesota is willing to pay $\$ 1300$ for a $10 \%$ increase in tree cover within 100 meters of their home and over $\$ 800$ for a $10 \%$ increase in tree cover within 250 meters of their home. Assuming that each ash tree contributes $\$ 2100$ of value to surrounding homes over a 30 -year time horizon, and using a discount rate of $2 \%$, the annualized net benefit of each ash tree is $\$ 94$. This estimate is similar to that produced by the National Tree Benefit Calculator for a 15 -inch diameter green ash tree. The Calculator yields an estimate of $\$ 147$ in benefits from each ash tree each year to the residents of St. Paul (St. Paul Parks and Recreation 2015).
} 
Table 2 Initial parameter values for simulation

\begin{tabular}{|c|c|c|}
\hline Parameter & Description & Initial value \\
\hline$\rho$ & Discount rate & 0.02 \\
\hline $\bar{V}$ & $\begin{array}{l}\text { Annual net benefits to uninfested } \\
\text { municipality for each year it remains } \\
\text { uninfested (\$ million) }\end{array}$ & 1.88 \\
\hline$V(0)$ & $\begin{array}{l}\text { Annual net benefits when a municipality is } \\
\text { infested and there is no transfer payment (\$ } \\
\text { million) }\end{array}$ & 0.88 \\
\hline$b$ & $\begin{array}{l}\text { Linear parameter, net benefits of ash trees in } \\
\text { infested municipality as a function of } \\
\text { transfer payments }\end{array}$ & -0.273 \\
\hline$c$ & $\begin{array}{l}\text { Quadratic parameter, net benefits of ash trees } \\
\text { in infested municipality as a function of } \\
\text { transfer payments }\end{array}$ & -0.826 \\
\hline$P_{0}$ & Initial probability of spread & 0.5 \\
\hline$r$ & Growth rate in the probability of spread & 0.08 \\
\hline$\delta$ & $\begin{array}{l}\text { Efficacy of transfer payment in reducing } \\
\text { probability of spread }\end{array}$ & 0.5 \\
\hline$\gamma_{\mathrm{I}, U}$ & Bargaining power coefficients & 0.5 \\
\hline
\end{tabular}

We assume that the initial probability of spread between the infested and uninfested municipalities is $50 \%$. Consistent with the literature on the spread of emerald ash borer, we assume this probability grows over time according to the exponential growth function, $f(P(t))=r P(t)$, with intrinsic growth rate $r$ (Mercader et al. 2011). ${ }^{23}$ We set the growth rate equal to $8 \%$, which implies that if no bargaining agreement is reached, the probability of spread reaches $100 \%$ within 10 years. This is similar to anticipated spread rates for EAB as described by Kovacs et al. (2014). A positive transfer payment reduces the probability of spread by increasing control efforts in the infested municipality. Initially, we set the efficacy parameter, $\delta$, equal to 0.5 . We conduct a sensitivity analysis to determine the effect of a change in this parameter on our results. Similarly, we set the bargaining power parameters, $\gamma_{I}$ and $\gamma_{U}$, equal to 0.5 and explore the sensitivity of our results to changes in their relative values.

First, we simulate numerically the probability of spread over time in the uncoordinated outcome in order to define the disagreement outcome necessary to solve the Nash bargaining solution, i.e. $d_{I}$ and $d_{U}$ as defined in Eqs. (4)-(5). We then simulate the bargaining and firstbest outcomes described in the theoretical section. For each of these problems, we solve in discrete time the system of necessary and sufficient conditions for an optimum, as described

23 In the simulation, we constrain $P(t)$ to the interval $[0,1]$. However, $P(t) \leq 1$ is only. binding in the uncoordinated outcome with no transfer payment. It is straightforward to use a probability growth function that guarantees $P(t) \leq 1$, such as the logistic growth function. We test a version of the model using the logistic growth function for the probability of spread, such that $f(P(t))=r P(t)(1-P(t) / K)$ where $K=1$. The change in the growth function has the greatest implications for the uncoordinated outcome, but the change in the path of transfer payments under the bargaining or first-best solutions is minimal. With the logistic function, the path of transfer payments in the bargaining solution is slightly higher, which drives the probability of spread to zero in as many as eight periods, as opposed to nine periods with the exponential growth function. Social costs under bargaining fall roughly 300,000 dollars with the exponential function compared to the logistic function. Additional simulation results are available upon request. 
in the theoretical framework. ${ }^{24}$ For each problem, the system of equations solved includes complementary slackness conditions that reflect bounds on the transfer payment $(\tau(t) \geq 0)$ and on the probability of spread $(0 \leq P(t) \leq 1)$. We fix the terminal period for the bargaining and first-best problems at $T=10$ years to reflect that in the uncoordinated outcome, spread is certain within 10 years. ${ }^{25}$ To solve the bargaining problem, we implement the solution method proposed by Ehtamo et al. (1988), iterating over the Hamiltonian weights $\mu_{I}$ and $\mu_{U}$ and the optimal path of transfer payments until convergence. With the initial parameters specified in Table 2, the bargaining problem requires 20 iterations to converge, with final Hamiltonian weights of 1.287 and 0.194 for the infested and uninfested municipalities, respectively.

\section{Results}

Table 3 presents the uncoordinated, bargaining, and first-best solutions using the initial parameters from Table 2. The empirical results accord with the theoretical expectations for the case in which $\rho<f^{\prime}$ and $\mu_{I}>\mu_{U}$. The theory yields ambiguous results about whether the path of transfer payments in the two solutions is increasing or decreasing. In our application to $\mathrm{EAB}$, both are decreasing. As predicted by the theory, the path of transfer payments in the first-best solution declines more rapidly than that of the bargaining solution.

The first-best strategy shown in Table 3 represents a case of perfect coordination, where the path of transfer payments is chosen to maximize the sum of net benefits to both municipalities. In this solution, the transfer payment is paid at a higher level over time than in the bargaining solution: for example, the optimal path of transfer payments exceeds those on the bargaining transfer path by more than $100 \%$ during the first two periods. As a consequence, the probability of spread is driven to zero in three periods. This solution maximizes the present value of total net benefits at $\$ 24.259$ million. In the first-best solution, the nonmarket benefits in the infested municipality are sacrificed to reduce the probability of spread and protect the uninfested municipality's net benefits. As a result, the uninfested municipality is better off than in the bargaining outcome. The infested municipality is made slightly worse off, though not as worse off as in the uncoordinated outcome.

The first-best outcome is a theoretical construct because it would not be expected if the municipalities are not required to coordinate perfectly (say, if there is not a higher governmental authority requiring them to do so). Thus, the more likely scenarios are those for the uncoordinated and bargaining outcomes in Table 3. The uncoordinated outcome represents a worst-case scenario in which there is no transfer payment across municipalities, and therefore it represents the case where both play uncoordinated disagreement strategies. This likely occurs in most cases in practice where local governments are not forced to work together. Here, the pest spreads to the uninfested municipality with $100 \%$ probability in nine periods. This is in contrast to the first-best case in which the pest never spreads to the uninfested municipality. In the uncoordinated outcome, both municipalities are worse off individually:

\footnotetext{
${ }^{24}$ It is necessary to solve this system of equations rather than the optimization problem directly in order to leverage the linearization of the Hamiltonian proposed by Ehtamo et al. (1988). Solving the bargaining problem directly, even numerically, is difficult because of the highly nonlinear nature of the multiplicative objective functional in (8).

25 Selecting too short a time horizon reduces the chance of an agreement, because the benefit of the transfer payment is greatly reduced. Extending the time horizon further into the future has little effect on the nature of the bargaining outcome, which involves large payments to reduce the probability of spread early and declining payments thereafter to balance the present value of maintaining the stock of ash trees with the expected losses from spread. Furthermore, extremely lengthy agreements between municipalities are unlikely to be politically feasible. Our choice of $T$ in the simulation balances these considerations.
} 
Table 3 Main simulation results

\begin{tabular}{|c|c|c|c|c|c|}
\hline \multirow[t]{2}{*}{ Time period } & \multirow{2}{*}{$\begin{array}{l}\text { Uncoordinated } \\
P(t)\end{array}$} & \multicolumn{2}{|c|}{ Bargaining } & \multicolumn{2}{|c|}{ First best } \\
\hline & & $\tau(t)$ & $P(t)$ & $\tau(t)$ & $P(t)$ \\
\hline 1 & 0.540 & 0.290 & 0.395 & 0.719 & 0.181 \\
\hline 2 & 0.583 & 0.247 & 0.303 & 0.363 & 0.013 \\
\hline 3 & 0.630 & 0.208 & 0.224 & 0.029 & - \\
\hline 4 & 0.680 & 0.171 & 0.156 & - & - \\
\hline 5 & 0.735 & 0.136 & 0.101 & - & - \\
\hline 6 & 0.793 & 0.103 & 0.058 & - & - \\
\hline 7 & 0.857 & 0.072 & 0.026 & - & - \\
\hline 8 & 0.925 & 0.043 & 0.007 & - & - \\
\hline 9 & 1 & 0.015 & - & - & - \\
\hline 10 & 1 & - & - & - & - \\
\hline Total transfer payments & - & 1.225 & & 1.103 & \\
\hline Net benefits, infested & 8.063 & 8.750 & & 8.330 & \\
\hline Net benefits, uninfested & 10.213 & 14.771 & & 15.928 & \\
\hline Net benefits, total & 18.276 & 23.522 & & 24.259 & \\
\hline Social cost & 5.983 & 0.737 & & - & \\
\hline
\end{tabular}

All sums are in present value and millions of dollars. Social cost is calculated as the difference between outcomes when the bargaining solution is substituted into the first-best objective functional

the uninfested municipality loses more than $\$ 5$ million relative to the first-best solution; the infested municipality loses $\$ 267,000$ relative to the first-best solution. More importantly, social costs, defined as the difference in maximum total net benefits under the first-best outcome and total net benefits using the social planner's objective function but without the transfer payment, are nearly $\$ 6$ million. Interestingly, this is considerably more than the total cost of transfers, even in undiscounted terms, under both the first-best and bargaining outcomes. Clearly, the uncoordinated outcome is to be avoided from both invasive species spread and social cost perspectives.

Table 3 also presents the outcome when both parties reach a Nash bargaining agreement. Our model reflects a case in which there are potential gains from bargaining, as reflected by expression (6). In the bargaining outcome, transfer payments reduce the probability of spread to zero within nine periods. The present value of total net benefits is nearly $30 \%$ higher than in the uncoordinated case. They are closer to the first-best outcome than the uncoordinated case, but still fall short of that maximum. The social costs associated with the bargaining solution are $\$ 737,000$ relative to the first-best transfer path. Due to the costs of greater control and discounting, the uninfested municipality will pay a much lower path of transfers to the infested municipality over time, and the probability of spread will not be driven to zero nearly as fast as in the first-best outcome. While the first-best outcome is obviously the preferred one, it would not be expected without some command and control by, for example, a higher government authority, because the infested municipality is made worse off by more than $\$ 400,000$ in the first-best outcome relative to the bargaining outcome. In the case with symmetric bargaining power, the uninfested municipality prefers this solution individually and has strong incentives to bargain. This said, the bargaining outcome is not 


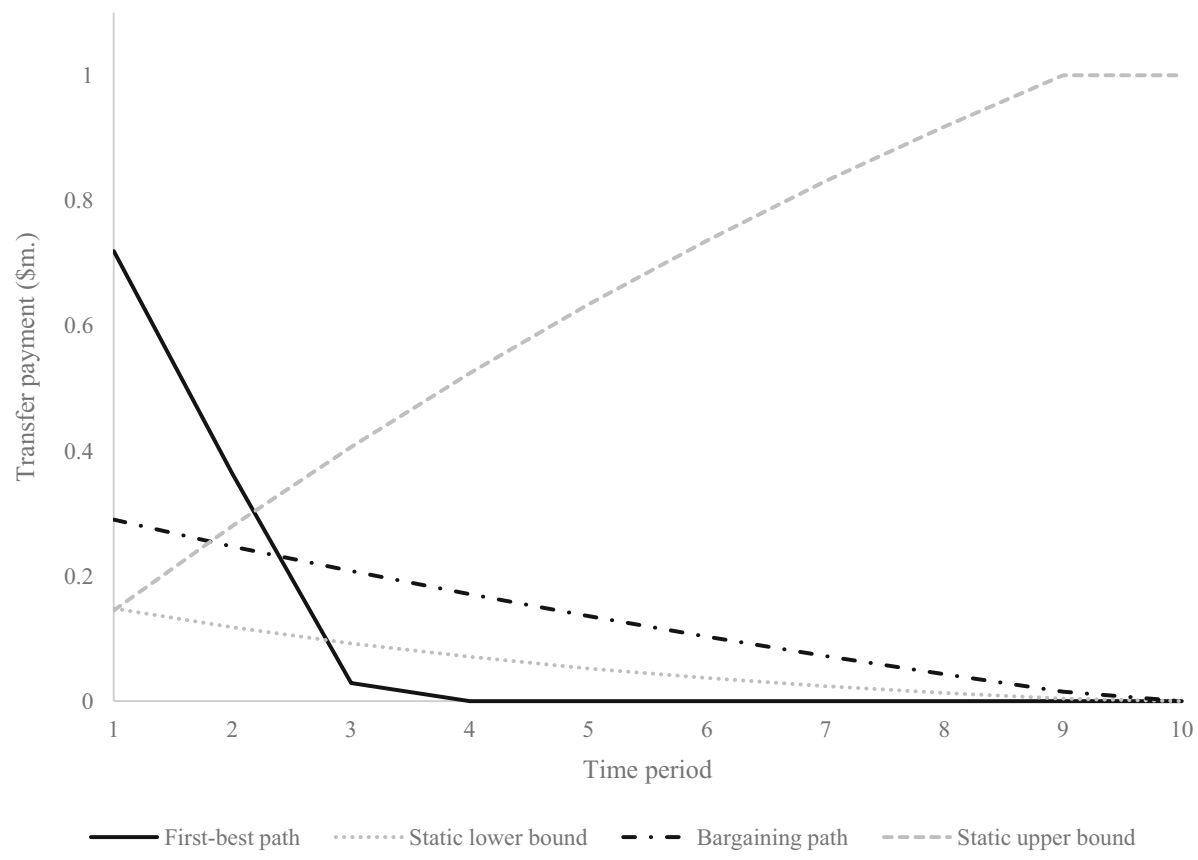

Fig. 1 Path of transfer payments for first-best and bargaining solutions. Notes Static lower and upper bounds represent, respectively, the loss in net benefits to the infested municipality from undertaking greater control and the expected gain to the uninfested municipality from an agreement in each period

necessarily a panacea for society, because given the transfer path, it clearly requires some long-term provision for parties to bargain that might not be present in practice.

An interesting interpretation of the differences in our outcomes can be gathered from Fig. 1, which illustrates the agreement region through time, which lies between the static upper and lower bounds for the transfer payment path in (7). Greater distance between these bounds is associated with greater scope for a bargaining agreement. If the transfer payment lies outside these bounds, it does not satisfy (7) for a single time period (although the solution still satisfies (6) for the problem's full time horizon). In the figure, we see that the optimal path of transfer payments in the bargaining solution lies outside of the agreement region prior to the second period and passes between the bounds thereafter. The optimal path of transfer payments in the bargaining solution therefore exceeds the per-period maximum willingness to pay of the uninfested municipality early in the problem, but this cost is offset as benefits accrue from bargaining in later periods because the spread of the invasive species is reduced. Clearly, bargaining requires a longer-term commitment than just a few periods in order to be successful within the context of our problem.

\subsection{Sensitivity Analysis}

While the parameters in Table 2 were calibrated using information from the EAB infestation in the Twin Cities, and under the assumption that the municipalities have equal bargaining power, it is instructive to consider changes to the model parameters in order to gauge the effectiveness of bargaining in reducing social costs relative to the uncoordinated outcome. The first important consideration is the fact that one of the municipalities may hold a bar- 
Table 4 Effect of bargaining power on the bargaining path of transfer payments

\begin{tabular}{lcccll}
\hline Time period & $\gamma_{U}=0.05$ & $\gamma_{U}=0.25$ & $\gamma_{U}=0.50$ & $\gamma_{U}=0.75$ & $\gamma_{U}=0.95$ \\
\hline 1 & 0.099 & 0.183 & 0.290 & 0.431 & 0.770 \\
2 & 0.114 & 0.173 & 0.247 & 0.328 & 0.334 \\
3 & 0.128 & 0.163 & 0.208 & 0.230 & - \\
4 & 0.141 & 0.154 & 0.171 & 0.138 & - \\
5 & 0.154 & 0.146 & 0.136 & 0.052 & - \\
6 & 0.165 & 0.138 & 0.103 & - & - \\
7 & 0.176 & 0.131 & 0.072 & - & - \\
8 & 0.187 & 0.124 & 0.043 & - & - \\
9 & 0.196 & 0.117 & 0.015 & - & - \\
10 & 0.206 & 0.111 & - & - & - \\
Ratio of Hamiltonian & 63.000 & 13.256 & 6.634 & 3.252 & 0.814 \\
$\quad$ weights $\left(\mu_{I} / \mu_{U}\right)$ & 1.416 & 1.331 & 1.225 & 1.152 & 1.098 \\
Total transfer & & & & & \\
payments & 8.903 & 8.867 & 8.750 & 8.601 & 8.280 \\
Net benefits, infested & 12.950 & 13.761 & 14.771 & 15.460 & 15.972 \\
Net benefits, & & & & & \\
$\quad$ uninfested & 21.853 & 22.628 & 23.522 & 24.061 & 24.252 \\
Net benefits, total & 3.577 & 4.352 & 5.246 & 5.785 & 5.976 \\
Bargaining net gains & 2.406 & 1.631 & 0.737 & 0.198 & 0.007 \\
Social cost & & & & & \\
\hline
\end{tabular}

$\gamma_{U}$ is the bargaining power coefficient for the uninfested municipality. All sums are in present value and millions of dollars. Bargaining net gains is the sum of present value net gains to the infested and uninfested municipality, calculated relative to the uncoordinated outcome. Social cost is calculated as the difference between outcomes when the bargaining solution is substituted into the first-best objective functional

gaining power advantage, which would alter the relative values of the parameters $\gamma_{I}$ and $\gamma_{U}$. Differences in these parameters may arise due to a variety of factors, such as underlying differences in political capital across the two municipalities.

A change in these parameters alters the relative magnitudes of the Hamiltonian weights in the bargaining problem. Consider, for example, the case in which the infested municipality holds less bargaining power than the uninfested municipality. A decrease in $\gamma_{I}$, leads to an increase in the Hamiltonian weight for the uninfested municipality, which places relatively greater weight on the uninfested municipality's net gains from bargaining in the Hamiltonian for the bargaining problem. Table 4 describes the change in the path of transfer payments under bargaining when one municipality has an advantage in terms of bargaining power. Moving across the columns from left to right, relative bargaining power shifts toward the uninfested municipality. The effect of this change is to reduce the ratio of the Hamiltonian weights, $\mu_{I} / \mu_{U}$. When the ratio equals 1 , the Hamiltonian weights of the two municipalities are identical and bargaining attains the first-best solution.

We find that it is better for society if the uninfested municipality holds more bargaining power because a more efficient transfer path is chosen that is closer to the social planner's path. Intuitively, greater bargaining power for the uninfested municipality is required to induce the infested municipality to undertake greater control. As the uninfested municipality gains bargaining power, the duration of the path of transfer payments becomes shorter and 
the bargaining solution converges toward the first-best path of transfer payments. At one extreme, when the uninfested municipality holds very little bargaining power $\left(\gamma_{U}=0.05\right)$, the path of transfer payments lasts the full 10 periods because the relative gains of the infested municipality become more important in driving the bargaining outcome. At the other extreme, when the infested municipality holds very little bargaining power $\left(\gamma_{U}=0.95\right)$, the path of transfer payments lasts only two periods and social costs are close to zero. The net benefits to the infested municipality decline when moving from left to right in Table 4 and the social costs associated with the bargaining solution decrease. It is not until the uninfested municipality holds nearly perfect bargaining power that the ratio of the weights equals 1 in this application and the bargaining outcome attains the first-best solution. However, even in cases when the uninfested municipality holds relatively little bargaining power (e.g., $\gamma_{U}=0.05$ ), the bargaining solution yields a substantial improvement over the uncoordinated outcome in terms of reducing social costs. For example, when $\gamma_{U}=0.05$, social costs in Table 3 are at their largest (\$2.406 million), but these costs represent a 60\% reduction ( $\$ 3.577$ million) relative to social costs in the uncoordinated outcome.

Figure 2 illustrates the bargaining transfer path and the region of agreement for two sets of bargaining power coefficients. In the upper panel, the infested municipality holds greater relative bargaining power than the uninfested municipality; in the lower panel, the uninfested municipality holds greater relative bargaining power. As Fig. 2 shows, bargaining power affects not only the optimal path of transfer payments, but also the static bounds that describe the scope for bargaining in the problem. When the uninfested municipality holds greater bargaining power, scope for bargaining increases relative to the case in which the infested municipality holds greater bargaining power. This is true despite the fact that bargaining generates a cost for the uninfested municipality in the form of the transfer payment. However, this cost is more than offset by protection of this municipality's nonmarket benefits by slowing or eliminating the spread of the invasive species. Clearly, the bargaining power of the uninfested municipality is a critical consideration in this bargaining problem.

Other parameters identified by the theory as important in driving the bargaining and first-best outcomes are the parameter relating a dollar spent on control to a reduction in the probability of spread $(\delta)$ and the rate of growth in the probability of spread $(r)$. Table 5 describes the change in the optimal path of transfer payments under bargaining with a change in $\delta$. When this parameter is small $(\delta=0.25)$, the optimal path for transfer payments is everywhere higher than when it is large $(\delta=1.5)$ and transfer payments continue for more periods. This higher and longer path of transfer payments compensates for a lower efficacy in preventing spread to the uninfested municipality. ${ }^{26}$ With lower efficacy, the relative net benefits gained through the transfer by the infested municipality are higher and those of the uninfested municipality lower than when $\delta$ is large. Although results are shown for the bargaining solution only, changes to $\delta$ imply similar qualitative changes to the first-best solution. The net effect of changes in the first-best and bargaining paths is that total social costs under bargaining increase as $\delta$ increases. Intuitively, more is lost to society by not perfectly coordinating control if the transfer payment is more effective in stemming the spread of the invasive species.

However, this is just part of the story concerning the efficacy parameter. Figure 3 illustrates the bargaining solution and bounds on the transfer payment for two values of $\delta$. As the efficacy parameter declines from 1.5 to 0.25 , the scope for bargaining also decreases, as illustrated by the decrease in the size of the agreement region. When the efficacy parameter is low, as

${ }^{26}$ If $\delta$ is a function of $P(t)$, e.g. $\delta=\delta / P(t)$, the sensitivity analysis suggests that a decline in $P(t)$ will put downward pressure on the path of transfer payments, resulting in lower total payments and a shorter path than in the case when $\delta$ is fixed. 


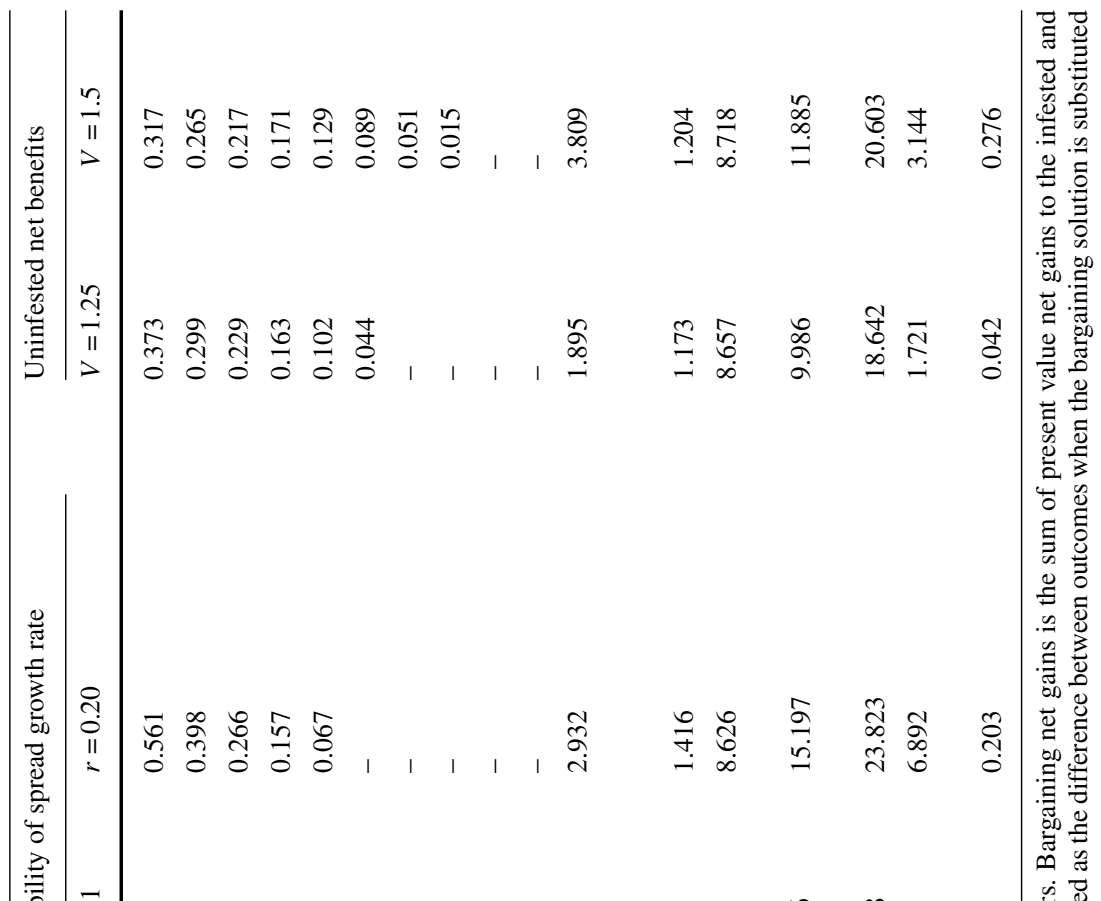

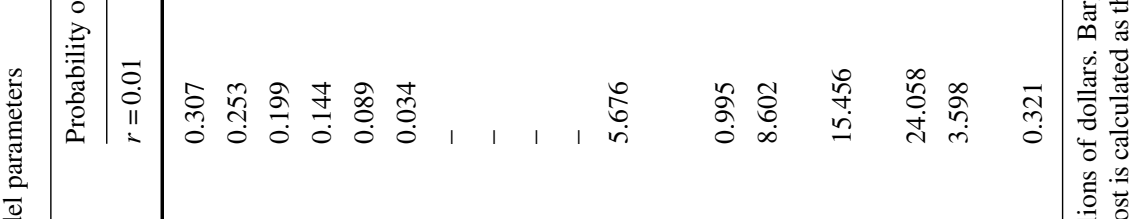

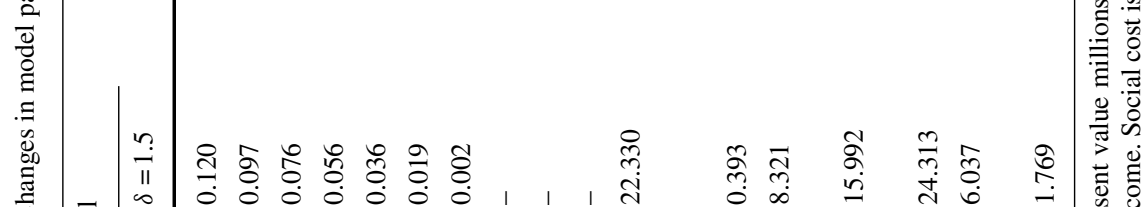

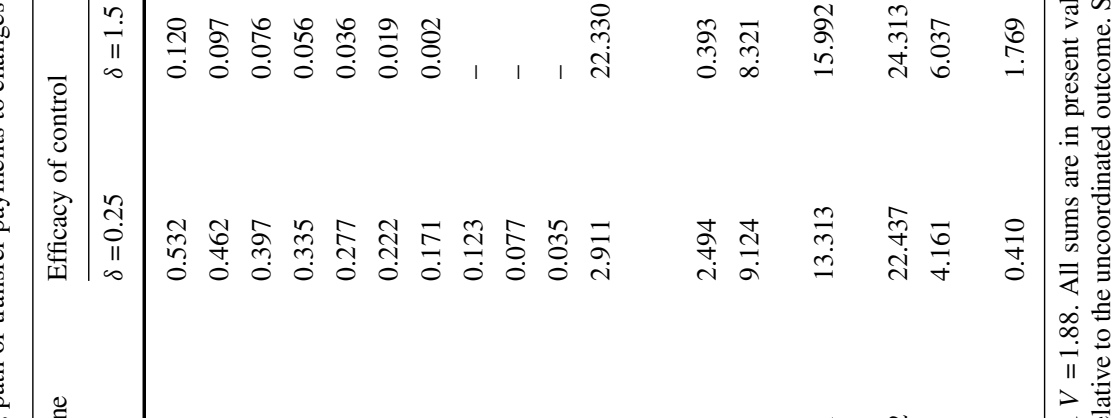

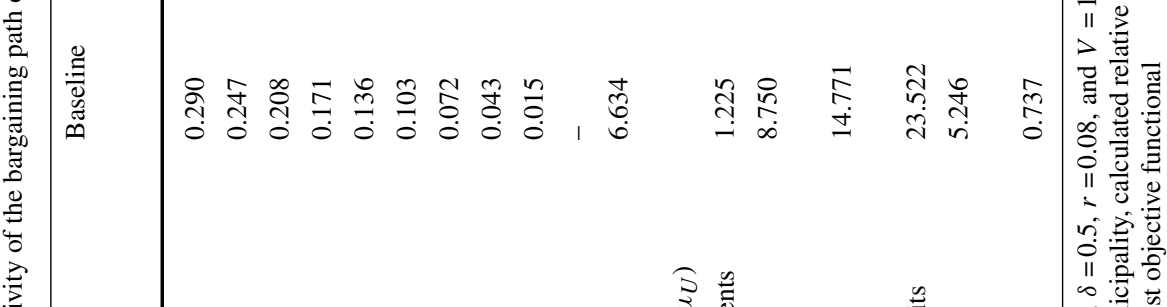

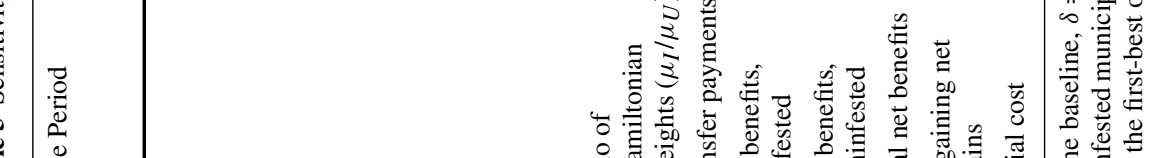

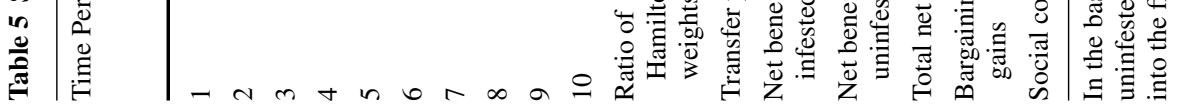



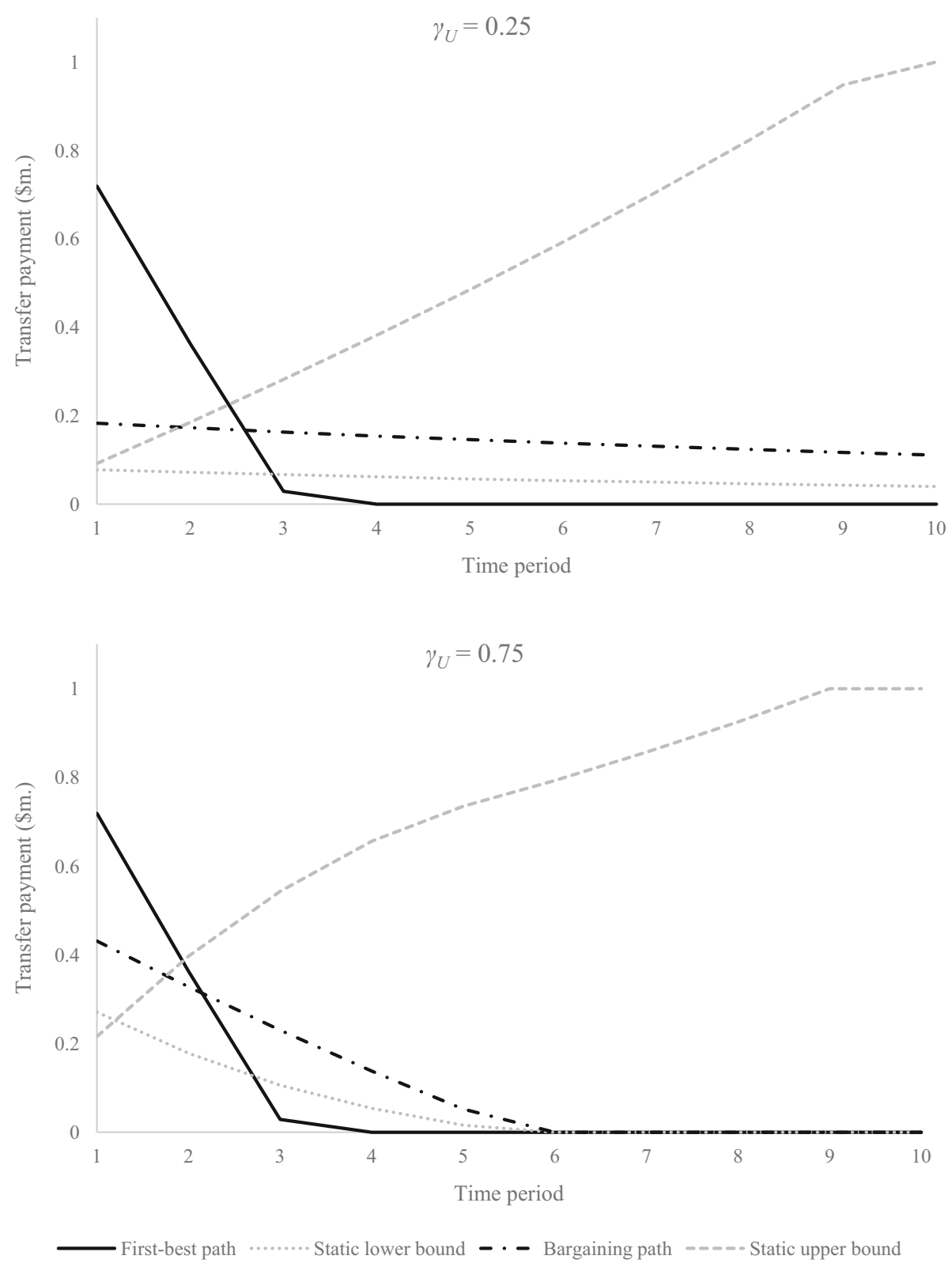

Fig. 2 Path of transfer payments in two bargaining power scenarios. Notes $\gamma_{U}$ is the bargaining power coefficient for the uninfested municipality. Static lower and upper bounds represent, respectively, the loss in net benefits to the infested municipality from undertaking greater control and the expected gain to the uninfested municipality from an agreement in each period

in the lower panel of Fig. 3, there is in fact no scope for bargaining in the first two periods of the problem (the lower bound lies above the upper bound). This is in contrast to the case in which the efficacy parameter is high, as in the upper panel of Fig. 3, where scope exists for a bargaining problem lasting fewer than two periods. 

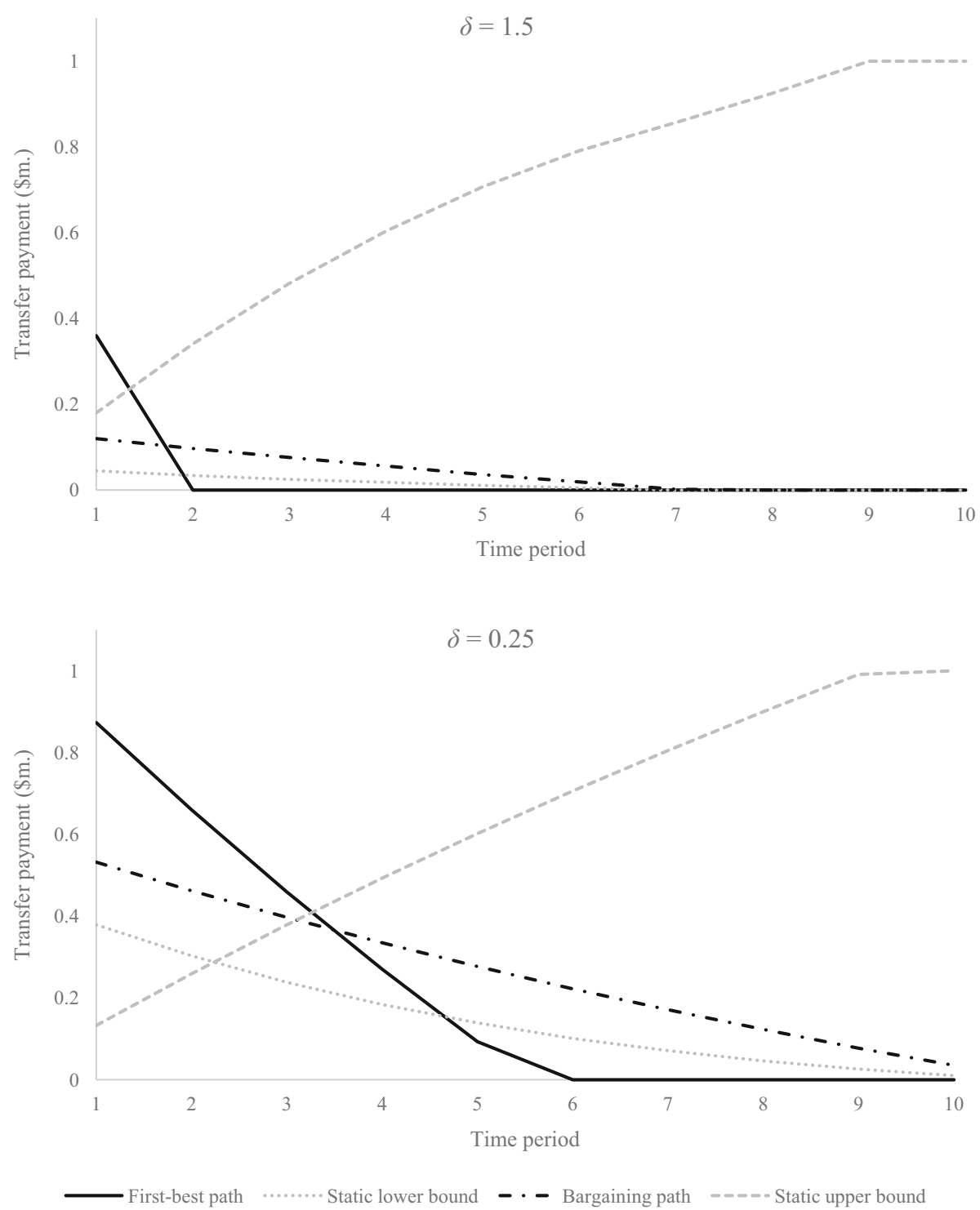

Fig. 3 Bargaining transfer payment path under two scenarios for the efficacy of the transfer payment in reducing the probability of spread. Notes $\delta$ is the efficacy of the transfer payment in reducing the probability of spread. Static lower and upper bounds represent, respectively, the loss in net benefits to the infested municipality from undertaking greater control and the expected gain to the uninfested municipality from an agreement in each period

Table 5 also describes how a change in the natural growth rate of spread for the invasive species affects the bargaining solution. As this growth rate increases, the present value of the stream of transfer payments from the uninfested to the infested municipality increases. The gain to bargaining, relative to the uncoordinated outcome increases monotonically from $\$ 3.6$ million at a growth rate of $1 \%$ to $\$ 6.9$ million at a growth rate of $20 \%$. However, the 
social costs of bargaining vary nonlinearly with $r$, attaining their lowest values when the growth rate of spread is either very low or very high. In either case, the optimal path of transfer payments involves larger payments early in the problem in order to eliminate the probability of spread quickly. When the growth rate is low, this approach is optimal because the costs of eliminating spread early in the problem are also relatively low. When the growth rate is high, this approach is optimal because the costs of allowing the pest to grow early in the problem are very high. For intermediate values of $r$, the optimal path of transfer payments under bargaining is longer and the social costs of bargaining increase, reaching a peak of $\$ 0.874$ million when the growth rate is $10 \%$.

In addition to these parameters, the maximum loss to the uninfested municipality from becoming infested $(\bar{V}-V(0))$ plays an important role in the bargaining and first-best solutions (Eqs. 12 and 17), as well as the difference between them (see Eq. 18). By altering the parameter $\bar{V}$, we can capture the effect of preventative measures undertaken by the uninfested municipality to reduce the probability of spread. For example, Minneapolis has undertaken a campaign of preemptive tree removal, particularly in areas adjacent to infested portions of St. Paul. The removal of these trees would reduce the value of $\bar{V}$ by reducing non-market benefits derived from tree cover and by incurring tree removal costs, even when the municipality remains uninfested.

Table 5 presents results as $\bar{V}$ decreases from its baseline value of $\$ 1.88$ million. As $\bar{V}$ declines to $\$ 1.25$ million, the total amount of transfer payments (in present value) and the duration of transfer payments decrease. These results are driven by a decline in the uninfested municipality's net gains from bargaining. This shifts the bargaining advantage toward the uninfested municipality, as reflected by an increasing Hamiltonian weight relative to that of the infested municipality (illustrated by the decline in the ratio of Hamiltonian weights in the table). The qualitative effect of a decrease in $\bar{V}$ is thus the same as that of an increase in the uninfested municipality's bargaining power parameter in Table 4. While a decrease in $\bar{V}$ leads to a decline in the social costs of bargaining, it also decreases net gains from bargaining relative to the uncoordinated outcome. This outcome is intuitive: to the extent that a municipality preventatively removes its own trees, the gains from sharing in the costs of control in the infested municipality decline.

Finally, we examine the sensitivity of the bargaining outcome to the specification of the terminal period. We find that for a time horizon shorter than 4 years, no bargaining solution exists that yields net gains to both municipalities. In this case, the solution reverts to the uncoordinated outcome and the maximum level of social costs. Beyond this minimum time horizon, the qualitative trajectory of the bargaining path of transfer payments is invariant with respect to $T$. Specifically, the path involves large payments early in the problem (which quickly reduces the probability of spread) and declining payments thereafter to balance the present value of maintaining the stock of ash trees with the expected losses from spread.

\section{Conclusions}

We have examined scope for bargaining in invasive species problems, where spread to adjacent locations is dictated by employment of costly controls and species-specific parameters. Our model considers a dynamic setting that captures necessary stylized features of invasive species biology and control, as well as negotiation between adjacent municipalities or individuals. In this problem, we consider cooperation through a transfer payment made from an uninfested municipality to an infested one, in return for greater controls taken by the infested 
locality to stem the spread. These greater controls imply that the infested municipality agrees to forego nonmarket benefits in early periods in order to protect the uninfested municipality's nonmarket benefits, either through delaying or removing the possibility of spread.

We consider Nash bargaining as a mechanism for negotiation, where municipalities can have different relative bargaining power and where disagreement outcomes become relevant to the bargaining problem. We use our model to compare the optimal transfer paths in the Nash bargaining game with the first-best path obtained under the perfectly cooperative, socially optimal problem where joint net benefits across municipalities are maximized. We identify parameters critical in determining the divergence in these paths over time. The most important factors are the relative bargaining power each municipality holds, the efficacy of the transfer payment in reducing invasive species spread, the species-specific growth rate in the probability of spread, and the level of nonmarket benefits affected by the invasive species. We also derive a time-dependent static agreement region representing the possible transfer payment paths that could be chosen over time in a Nash bargaining solution, showing how these are sensitive to parameters shaping the incentives for each municipality to enter into an agreement.

A simulation calibrated using a currently relevant example of emerald ash borer in the Twin Cities of Minneapolis and St. Paul, Minnesota is used to examine the results of our model. Each city is currently engaged in different types of control strategies, which is consistent with an uncoordinated, privately optimal outcome. We therefore use this case to evaluate the magnitude of social costs under an uncoordinated outcome and a possible Nash bargaining outcome relative to the first-best, full-cooperation outcome.

The simulation reveals several new insights that may be used to support future invasive species management. Most importantly, ensuring cooperation of any kind among adjacent localities is critical not only in reducing spread rates but in reducing the social costs associated with costly control of an invasive species. Transfer payments, mentioned in the literature as a means for cooperation, are one vehicle to do so. Further, our comparison of bargaining and the uncoordinated outcomes shows that in order for bargaining to work and to achieve an outcome close to the first-best one, long-term agreements may be necessary. This suggests that perhaps a higher level of governmental authority has a role to play in facilitating cooperation and managing the nature of agreements, even when parties are left to negotiate any transfers on their own, local terms. Interestingly, and unexpectedly, we find that bargaining outcomes are closer to the theoretical first-best if the uninfested municipality has greater bargaining power relative to the infested municipality. This is true regardless of the rate of population growth for the invasive species or the efficacy of the transfers in reducing the probability of spread. Finally, we cannot ignore the biology of the invasive species when evaluating the economics behind this problem. A higher rate of spread implies a larger gain from bargaining relative to the uncoordinated outcome, though social costs peak at an intermediate level of spread and decline as spread increases further. For the range in which social costs are largest, an alternative policy approach may outperform bargaining in terms of attaining the first-best solution. However, cases where there is a greater efficacy of the transfer in ensuring effective control also are ones where there is a much greater scope for bargaining, but at the same time higher social costs from not attaining the first-best outcome.

In order to accommodate the dynamics that describe the spread of the invasive species between municipalities, we have used the simplest form of a bilateral bargaining problem. In practice, however, it is likely that many nearby municipalities face a risk of spread from one or more infested areas. Our framework could be directly applied to the case in which two coalitions of municipalities negotiate with one another to slow or prevent the spread of a pest. However, we do not model how coalitions form and how their membership composition would 
affect the bargaining outcome. It would be a fruitful, though technically complex, extension to consider spread dynamics within the context of a general multilateral bargaining problem. We suspect though that our results about the importance of bargaining power would continue to apply to a situation in which coalitions form in order to facilitate negotiations across infested and uninfested municipalities or agents. Specifically, the composition of coalitions and their resulting sizes will carry implications for their relative bargaining power, which influences the social costs of bargaining and the desirability of intervention by a higher governmental authority to orchestrate a regional approach to invasive species control.

Finally, an interesting extension would be to consider uncertainty in the nonmarket benefits at risk from the spread of pests in a bilateral bargaining problem. In our model, uncertainty would come into the bargaining solution through several channels, all of which affect the cost of higher-level controls (lost nonmarket benefits) undertaken in the infested municipality, and the benefits of the transfer payment to the uninfested municipality in terms of avoided losses in nonmarket benefits. If uncertainty is symmetric, i.e., each municipality faces the same uncertainty, then our basic results comparing the bargaining and uncoordinated outcomes to the first best would likely continue to hold, albeit with a different level of the transfer payment that depends on expectations of nonmarket benefits. The presence of asymmetric information, where one municipality has better information than the other about its own nonmarket benefits, could matter to the results, and would be important when adjacent actors are not the type of transparent governments we consider.

\section{References}

Aadland D, Sims C, Finoff D (2015) Spatial dynamics of optimal management in bioeconomic systems. Comput Econ 45:545-577

Amacher GS, Malik AS (1998) Instrument choice when regulators and firms bargain. J Environ Econ Manag 35:225-241

Amacher GS, Ollikainen M, Koskela E (2012) Corruption and forest concessions. J Environ Econ Manag 63:92-104

Bhat MG, Huffaker RG (2007) Management of a transboundary wildlife population: a self-enforcing cooperative agreement with renegotiation and variable transfer payments. J Environ Econ Manag 53:54-67

Bhat MG, Huffaker RG, Lenhart SM (1993) Controlling forest damage by dispersive beaver populations: centralized optimal management strategy. Ecol Appl 3:518-530

Bhat MG, Huffaker RG, Lenhart SM (1996) Controlling transboundary wildlife damage: modeling under alternative management scenarios. Ecol Model 92:215-224

Binmore K, Rubinstein A, Wolinsky A (1986) The Nash bargaining solution in economic modeling. RAND J Econ 17:176-188

Büyüktahtakin IE, Haight RG (2017) A review of operations research models in invasive species management: state of the art, challenges, and future directions. Ann Oper Res. https://doi.org/10.1007/s10479-0172670-5

Calvo E, Rubio SJ (2012) Dynamic models of international environmental agreements: a differential game approach. Int Rev Environ Resour Econ 6:289-339

City of St. Paul (2014) Citywide EAB management strategies. https://www.stpaul.gov/departments/parksrecreation/natural-resources/forestry/disease-pest-management/citywide-eab. Accessed 6 March 2018

Cobourn KM, Burrack HJ, Goodhue RE, Williams JC, Zalom FG (2011) Implications of simultaneity in a physical damage function. J Environ Econ Manag 62:278-289

Ehtamo H, Ruusunen J, Kaitala V, Hamalainen RP (1988) Solution for a dynamic bargaining problem with an application to resource management. J Optim Theory Appl 59:391-405

Epanchin-Niell RS, Wilen JE (2012) Optimal spatial control of biological invasions. J Environ Econ Manag 63:260-270

Epanchin-Niell RS, Wilen JE (2014) Individual and cooperative management of invasive species in humanmediated landscapes. Am J Agric Econ 97:180-198 
Epanchin-Niell RS, Hufford MB, Aslan CE, Sexton JP, Port JD, Waring TM (2010) Controlling invasive species in complex social landscapes. Front Ecol Environ 8:210-216

Feder G, Regev U (1975) Biological interactions and environmental effects in the economics of pest control. J Environ Econ Manag 2:75-91

Fiege M (2005) The weedy west: mobile nature, boundaries, and common space in the Montana landscape. West Hist Q 36:22-47

Frisvold GB, Caswell MF (2000) Transboundary water management: game-theoretic lessons for projects on the US-Mexico border. Agric Econ 21:101-111

Gertler M, Trigari A (2006) Unemployment fluctuations with staggered Nash wage bargaining. In: NBER working paper 12498, national bureau of economic research, Cambridge, MA

Great Lakes Commission (2012) Restoring the natural divide: separating the Great Lakes and Mississippi River Basins in the Chicago area waterway system. https://www.glc.org/work/CAWS/reports. Accessed 6 March 2018

Grimsrud KM, Chermak JM, Hansen J, Thacher JA, Krause K (2008) A two-agent dynamic model with an invasive weed diffusion externality: an application to Yellow Starthistle (Centaurea solstitialis L.) in New Mexico. J Environ Manag 89:322-335

Hamalainen RP, Kaitala V, Haurie A (1984) Bargaining on whales: a differential game model with Pareto optimal equilibria. Oper Res Lett 3:5-11

Herms DA, McCullough DG, Smitley DR, Sadof CS, Cranshaw W (2014) Insecticide options for protecting ash trees from emerald ash borer, 2nd edn. North Central IPM Center, Urbana-Champaign, Illinois

Koskela E, Schöb R (1999) Alleviating unemployment: the case for green tax reforms. Eur Econ Rev 43:1723-1746

Koskela E, Schöb R, Sinn H-W (1998) Pollution, factor taxation and unemployment. Int Tax Pub Financ 5:379-396

Kovacs KF, Haight RG, McCullough DG, Mercader RJ, Siegert NW, Liebhold AM (2010) Cost of potential emerald ash borer damage in U.S. communities, 2009-2019. Ecol Econ 69:569-578

Kovacs KF, Haight RG, Mercader RJ, McCullough DG (2014) A bioeconomic analysis of an emerald ash borer invasion of an urban forest with multiple jurisdictions. Resour Energy Econ 36:270-289

Liu Y, Sims C (2016) Spatial-dynamic externalities and coordination in invasive species control. Resour Energy Econ 44:23-38

Mazzanti M (2001) The role of economics in global management of whales: re-forming or re-founding IWC? Ecol Econ 36:205-221

McCullough DG, Mercader RJ (2012) Evaluation of potential strategies to SLow Ash Mortality (SLAM) caused by emerald ash borer (Agrilus planipennis): SLAM in an urban forest. Int J Pest Manag 58:9-23

Melo F (2014) In emerald ash borer fight, St. Paul sticks with strategy of removing trees. St. Paul Pioneer Press, Saint Paul, p 24

Mercader RJ, Siegert NW, Liebhold AM, McCullough DG (2011) Influence of foraging behavior and host spatial distribution on the localized spread of the emerald ash borer, Agrilus planipennis. Popul Ecol 53:271-285

Minneapolis Park and Recreation Board (2014) Ash canopy replacement plan. https://www.minneapolisparks. org/_asset/3nrmra/terrestrial-eab-ash-canopy-replacement-plan.pdf. Accessed 6 March 2018

Munro GR (1979) The optimal management of transboundary renewable resources. Can J Econ 12:357-376

Nash JF Jr (1950) The bargaining problem. Econometrica 18:155-162

Olson LJ (2006) The economics of terrestrial invasive species: a review of the literature. Agric Resour Econ Rev 35:178-194

Osborne MJ, Rubinstein A (1994) A course in game theory. MIT Press, Cambridge

Sander H, Polasky S, Haight RG (2010) The value of urban tree cover: a hedonic property price model in Ramsey and Dakota Counties, Minnesota, USA. Ecol Econ 69:1646-1656

Sims C, Aadland D, Finnoff D (2010) A dynamic bioeconomic analysis of mountain pine beetle epidemics. J Econ Dyn Control 34:2407-2419

St. Paul Parks and Recreation (2015) Emerald ash borer: frequently asked questions. http://www.stpaul.gov/ DocumentCenter/View/78030. Accessed 6 March 2018

van der Ploeg F, de Zeeuw AJ (1992) International aspects of pollution control. Environ Resour Econ 2: 117-139

Wilen JE (2007) Economics of spatial-dynamic processes. Am J Agric Econ 89:1134-1144 